\title{
PENGENALAN SAINS SEJAK DINI MELALUI IT DAN ALAT PERAGA BAGI GURU PAUD DAN TK KECAMATAN POLOKARTO
}

\author{
Suparmi, Mohtar Yunianto*, Kusumandari \\ Program Studi Fisika, FMIPA Universitas Sebelas Maret \\ *mohtaryunianto@staff.uns.ac.id
}

\begin{abstract}
Abstrak
Telah dilakukan upaya dalam rangka mengenalkan sains bagi anak usia dini melalui pelatihan. Pelatihan ini diikuti oleh 46 Guru dari 23 sekolah PAUD dan TK se kecamatan Polokarto. Kegiatan dilaksanakan dalam 2 tahap, tahap pertama adalah pengenalan sains berbasis IT yaitu mengenalkan aplikasi Augmented Reality AR Animal dan Planet $A R$. Tahap kedua adalah pengenalan sains menggunakan alat peraga yaitu alat peraga kesetimbangan dan Angka digital. Berdasarkan kuisioner sebelum pelatihan sebagian besar belum dapat mengimplementasikan IT dan alat peraga dalam mengenalkan sains ke anak didik. Setelah pelatihan dari hasil kuisioner semua Guru dapat memanfaatkan media pembelajaran berbasis IT dan juga memahami dalam mengenalkan sains melalui alat peraga.
\end{abstract}

Kata kunci-sains, usia dini, berbasis IT, alat peraga, augmented reality

\section{Pendahuluan}

Pendidikan anak usia dini adalah suatu upaya yang ditujukan kepada anak sejak lahir sampai usia enam tahun yang dilakukan melalui pemberian rangsangan pendidikan untuk membantu pertumbuhan dan perkembangan jasmani dan rohani agar anak memiliki kesiapan dalam memasuki pendidikan lebih lanjut (Ariyanti, 2016). Usia dini merupakan kesempatan emas bagi anak untuk belajar, sehingga disebut usia emas (golden age) ( Uce, 2017). Pada kelompok ini anak memliki kemampuan yang luar biasa khususnya pada masa kanak-kanak awal.

Guru masih mengenalkan pembelajaran sains kepada anak dengan bercerita sehingga anak mudah bosan dan akibatnya anak kurang memahami tentang pembelajaran sains. Penerapan pembelajaran merupakan suatu kegiatan interaksi antara guru dan peserta didik dimana akan diakhiri dengan proses evaluasi hasil belajar (Rizal, 2014). Evaluasi atau penilaian adalah suatu cara untuk mengukur kemajuan pelaksanaan, keberhasilan dan perkembangan kognitif dan masalahnya yang berkaitan dengan hasil belajar yang diharapkan pada anak. Pembelajaran Sains dapat diartikan sebagai ilmu tentang alam atau yang mempelajari peristiwa-peristiwa yang terjadi di alam ( Narut dan Supardi, 2019). Sains adalah sistem tentang alam semesta yang diperoleh melalui pengumpulan data dengan observasi dan eksperimen terkontrol ( Laila dkk, 2016).

Pengalaman belajar yang diperoleh anak dari lingkungan, melalui cara mengamati, meniru dan bereksperimen yang berlangsung secara berulang-ulang, termasuk stimulasi yang akan mempengaruhi seluruh potensi dan kecerdasan anak. Oleh karena itu, diperlukan upaya yang mampu memfasilitasi anak dalam masa tumbuh kembangnya berupa kegiatan pendidikan dan pembelajaran sesuai dengan usia, kebutuhan dan minat anak. Pada hakikatnya sains sangat berhubungan langsung dengan anak melalui proses-proses alam yang terjadi disekeliling anak ( Izzudin, 2019). Pengenalan tentang sains hendaknya dilakukan sejak usia dini dengan kegiatan yang menyenangkan dan melalui pembiasaan agar anak mengalami proses sains secara langsung ( Mustika dan Nurwidaningsih, 2018). Hal itu dilakukan agar anak tidak hanya mengetahui hasilnya saja tetapi juga dapat mengerti proses dari kegiatan sains yang dilakukannya. 
Dalam kegiatan ini mitra adalah Guru PAUD dan TK se kecamatan Polokarto dimana ada dua hal utama yang menjadi kendala dalam proses pembelajaran berbasis Sains pada anak usia dini, bahwa Guru masih mengenalkan pembelajaran sains kepada anak dengan bercerita sehingga anak mudah bosan dan akibatnya anak kurang memahami tentang pembelajaran sains, berikutnya adalah minimnya alat peraga pembelajaran sains di sekolahsekolah mitra serta masih banyak yang belum faham pemanfaatanteknologi informasi baik melalui aplikasi maupun animasi dalam mengajarkan sains.

Berdasarkan kondisi tersebut akan sulit untuk memahamkan tentang sains pada anak usia dini apabila tidak dilakukan dengan metode yang tepat oleh karena itu perlu upaya yang sistematis terutama bagi Guru-guru di daerah tersebut agar dapat mengubah paradigma itu, yaitu melalui pembelajaran menggunakan metode-metode yang menarik dan dapat menumbuh kembangkan minat anak didik, melalui penggunaan aplikasi, program simulasi, animasi serta penggunaan alat peraga berbasis sains.

\section{Metode Pelaksanaan}

Melihat kondisi yang real terjadi di mitra bahwa pembelajaran konvensional yang sebelumnya di kenal, guru menjelaskan materi pembelajaran sains dengan bercerita, hal ini imajinasi anak kurang berkembang, apalagi jika dikaitkan dengan era Revolusi Industri 4.0, dimana agar siswa didik bisa kompetitif, kurikulum perlu orientasi baru, perlu ada terobosan dalam pola berfikir dan proses pembelajaran, sebab adanya Era Revolusi Industri 4.0, tidak hanya cukup Literasi Lama (membaca, menulis, \& matematika) sebagai modal dalam mengajar ( Anwar dkk, 2020).

Berdasarkan analisa permasalahan untuk mewujudkan target utama dari kegiatan yaitu menghasilkan anak didik yang mampu berfikir kritis, inovatif, kreatif, mandiri serta berorientasi pada proses berdasar dari pengalaman belajar, berkelanjutan. Kegiatan Pemberdayaan Guru ini dilaksanakan dengan metode Workshop yang dalam 2 tahapan besar yang dilaksanakan secara berkelanjutan, adapun kegiatannya tersebut sebagai berikut : Tahap pertama adalah pelatihan penggunaan aplikasi Augmented reality dalam pembelajaran melalui animasi maupun simulasi 3 Dimensi yaitu mengenalkan jenis hewan dan tata surya, peserta terlebih dahulu di minta untuk mengunduh kedua aplikasi di playstore, yaitu AR Animal dan planet AR, Tahap kedua adalah Pelatihan penggunaan kit alat peraga sains untuk lebih memahamkan materi pembelajaran sains, dalam ini menggunakan alat peraga kesetimbangan dan angka digital.

\section{Hasil dan Pembahasan}

Kegiatan yang dilalukan meruapakan upaya dalam rangka mengenalkan sains sejak dini bagi anak usia PAUD dan TK, adapun peserta dari kegiatan ini adalah Guru PAUD dan TK se kecamatan Polokarto sebanyak 46 Guru yang mewakili 23 sekolah, dimana Guru tersebut berada dibawah Majelis Pendidikan Dasar dan Menengah Aisyiyah Cabang Blimbing Kabupaten Sukoharjo. Sebelum dilakukan pelatihan dilakukan pengisian angket untuk mengetahui sejauh mana pemahaman Guru dalam mengenalkan sains sejak dini bagi anak. Hasil angket tersaji pada Tabel 1.

Terlihat dalam Tabel 1. Bahwa sudah banyak Guru yang memahami pembelajaran menggunakan IT akan tetapi baru sekitar $68 \%$ saja yang menggunakannya dalam pembelajaran, hal ini karena keterbatasan fasilitas yang ada, sebagain besar menggunakan handphone hanya untuk pengiriman tugas maupun pengerjaan tugas saat pandemi. Berkaitan dengan pembelajaran berbasis alat peraga hampir semua Guru memahami dan sudah menggunakan dalam pembelajaran, sebagian besar menggunakan jenis sentra Agama, akan tetapi penekanan pengenalan sains melalui alat peraga yang masih kurang.

Kegiatan yang pertama dilakukan adalah mengenalkan sains melalui IT, dalam kegiatan ini menggunakan aplikasi Augmented Reality, aplikasi yang digunakan ada 2, yaitu AR_Animal dan Planet AR, kedua aplikasi tersebut dapat di unduh secara gratis melalui playstore. 
Tabel 1. Angket pra pelatihan

\begin{tabular}{|c|c|c|}
\hline No & Uraian & Prosentase \\
\hline \multicolumn{3}{|c|}{ Berbasis IT } \\
\hline 1 & Memahami pembelajaran berbasis IT & $83 \%$ \\
\hline 2 & Menggunakan metode ini & $68 \%$ \\
\hline \multirow[t]{7}{*}{3} & Alat yang digunakan & \\
\hline & Komputer & $5 \%$ \\
\hline & Laptop & $33 \%$ \\
\hline & TV & $3 \%$ \\
\hline & LCD Proyektor & $18 \%$ \\
\hline & Handphone & $50 \%$ \\
\hline & Rekaman audio & $20 \%$ \\
\hline \multicolumn{3}{|c|}{ Berbasis Alat peraga } \\
\hline 1 & Mengetahui arti dan jenis Alat Peraga & $98 \%$ \\
\hline 2 & Menggunakan metode ini & $95 \%$ \\
\hline \multirow[t]{9}{*}{3} & Jenis yang digunakan & \\
\hline & Poster Warna & $53 \%$ \\
\hline & Sentra Balok & $78 \%$ \\
\hline & Sentra transportasi & $33 \%$ \\
\hline & Sentra Agama & $90 \%$ \\
\hline & Sentra Abacus & $8 \%$ \\
\hline & Sentra Keseimbangan & $28 \%$ \\
\hline & Sentra Berhitung & $48 \%$ \\
\hline & Puzle Angka & $65 \%$ \\
\hline
\end{tabular}

Aplikasi AR_Animal merupakan aplikasi berbasis Augmented Reality yang mengenalkan bentuk hewan, cara berjalan suara dan cara makan, untuk menggunakan Aplikasi ini adalah dengan mengunduh di playstore dengan nama AR_Animals seperti pada Gambar 1, kemudian dilakukan instalasi di handphone, untuk menggunakan aplikasi ini ada gambar yang di scan agar muncul gambar virtual di dalam handphone yang disebut marker seperti pada Gambar 2, dengan melakukan scan marker inilah yang memunculkan beraneka ragam hewan seperti ditunjukkan pada Gambar 3.

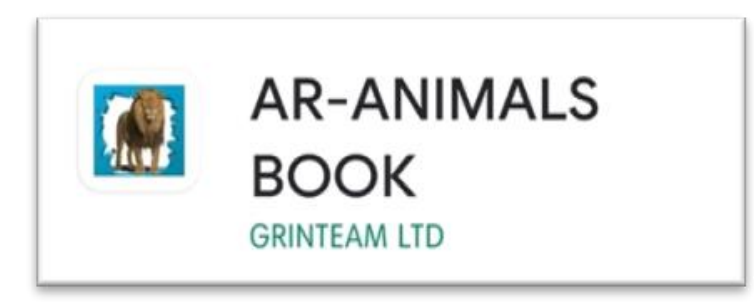

Gambar 1. Aplikasi AR-Animals 


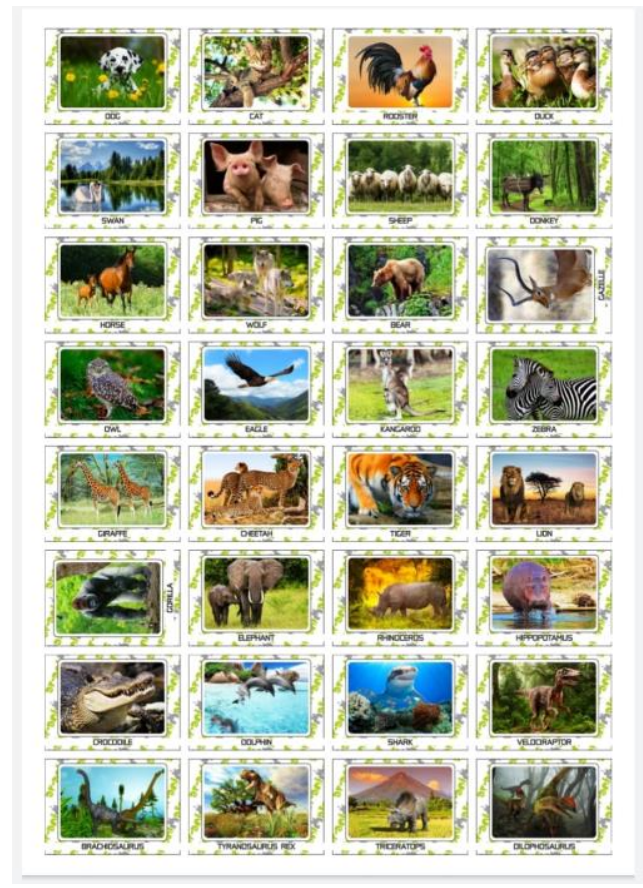

Gambar 2. Marker untuk AR-Animal
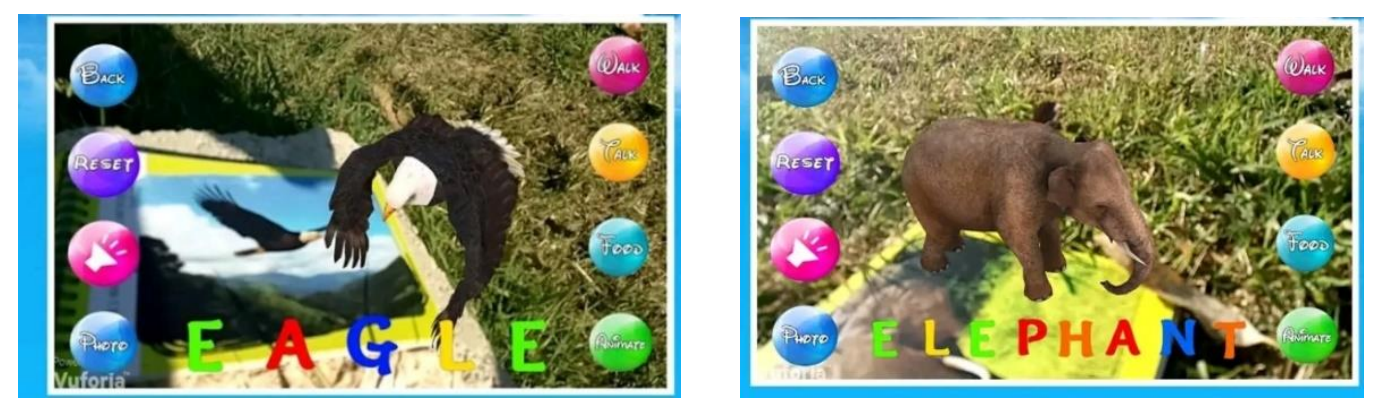

Gambar 3. Contoh hasil scan marker berupa Gambar virtual animasi 3 dimensi

Aplikasi ke dua yang dikenalkan adalah planet $A R$, merupakan aplikasi berbasis Augmented Reality untuk mengenalkan susunan tata surya dan Bulan, untuk aplikasi ini sudah tidak memerlukan marker, cukup di tempatkan di tempat yang terang sudah dapat memunculkan gambar virtual 3 dimensi. Gambar 4 merupakan aplikasi yang berada di playstore, Gambar 5 merupakan contoh implementasi penggunakan aplikasi ini

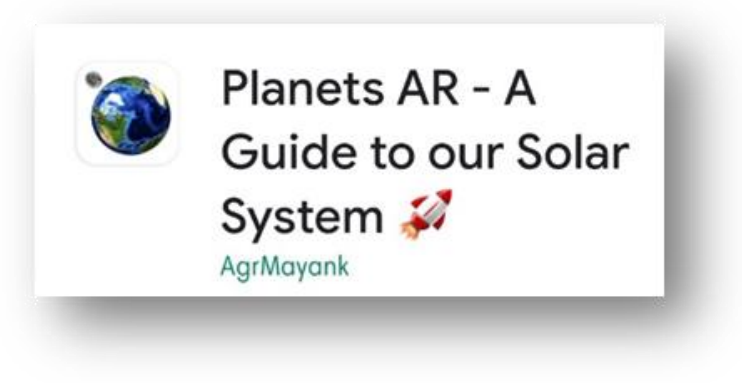

Gambar 4. Aplikasi Planet AR 

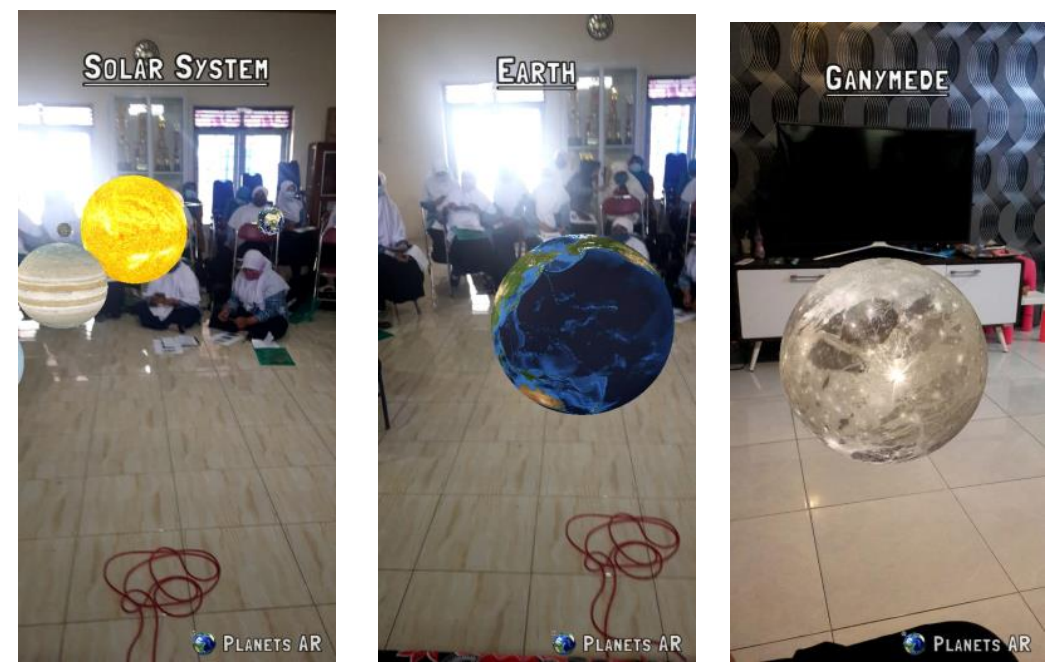

Gambar 5. Contoh implementasi Aplikasi

Dengan dikenalkan 2 aplikasi tersebut, para peserta sangat antusias untuk mencoba dan Sebagian peserta dapat menggunakan aplikasi tersebut dan sangat tertarik untuk mengenalkan ke anak didik, beberapa hal yang menjadi hambatan diantaranya adalah kurang support untuk beberapa handphone yang dimiliki peserta serta koneksi internet yang agak bermasalah untuk beberapa provider.

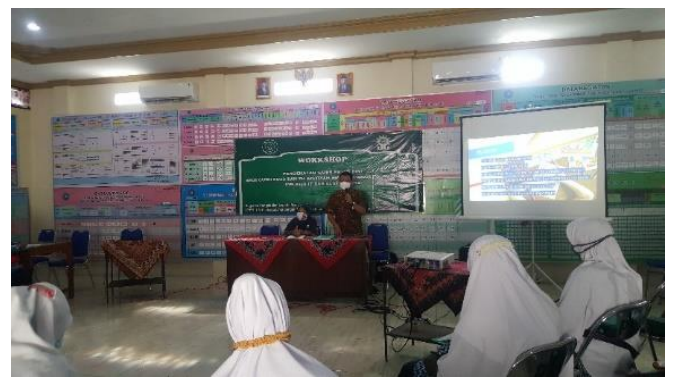

Gambar 6. Pemateri memberikan arahan cara menginstal dan menggunakan Aplikasi

Pelatihan berikutnya adalah implementasi alat peraga dalam mengenalkan sains kepada anak. Dalam pelatihan ini dikenalkan 2 alat peraga yaitu kesetimbangan yang merupakan hal yang sehari-hari di jumpai anak didik, konsep sains berkaitan dengan berat, massa, jumlah dan kesetimbangan di kenalkan dengan cara yang menarik, variasi jumlah bola dan variasi jarak dan Panjang kawat menjadi alat ini memiliki variasi yang banyak dalam mengenalkan sains, guru menjadi sangat antusias untuk mengikutinya. Alat peraga yang kedua adalah angka digital, dimana angka digital disusun dari balok kayu yang dapat dilepas dan dipasang sehingga ini menuntut ketelitian dan keseriusan bagi bagi Guru maupun bagi murid untuk memperlajarinya. Dalam kegiatan ini banyak dilakukan game dan quiz untuk meberikan contoh cara mengenalkan sains ke anak dengan cara yang menyenan gkan. Kedua jenis alat peraga tersebut dihibahkan ke 23 Sekolah peserta pelatihan.
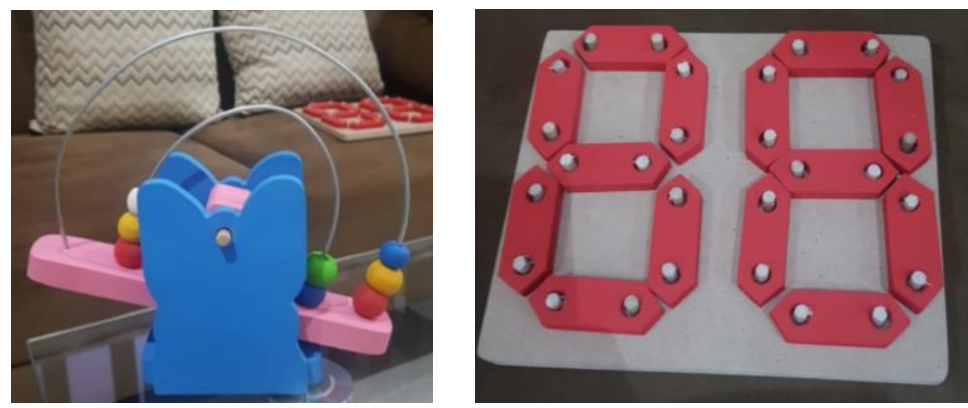
(a)

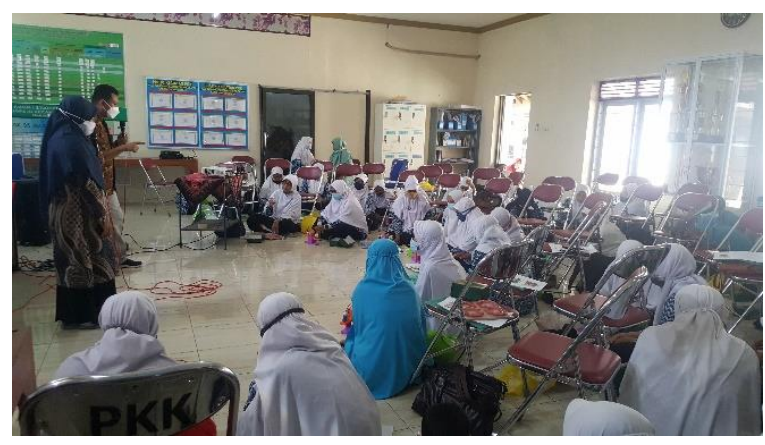

(b)

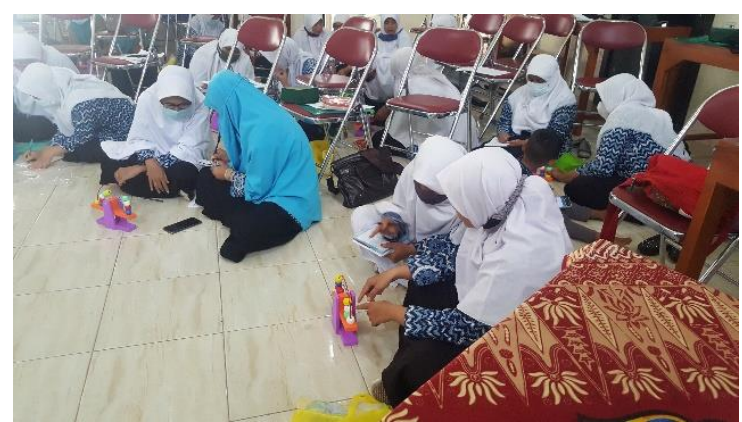

(c)

Gambar 7. (a). Alat peraga keseimbangan (b) Angka digital (c) Peserta mencoba alat peraga Kesetimbangan dan angka digital dengan antusias.

Setelah dilakukan pelatihan untuk 2 sessi kemudian diikuti dengan pengisian angket untuk mengetahui sejauh mana ketercapaian target dari kegiatan ini, hasilnya tersaji pada tabel 2 berikut

Tabel 2. Rekapitulasi angket setelah pelatihan

\begin{tabular}{ll}
\hline No $\quad$ Uraian & Prosentase \\
\hline Berbasis IT & \\
$1 \quad$ Memahami pembelajaran berbasis IT & $100 \%$ \\
2 & Memahami dalam penggunaan metode ini \\
Berbasis Alat peraga & $100 \%$ \\
$1 \quad$ Mengetahui arti dan jenis Alat Peraga & $100 \%$ \\
$\quad$ Mampu menggunakan alat peraga untuk mengenalkan & \\
$2 \quad$ sains & $100 \%$ \\
\hline
\end{tabular}

Dari tabel 2 terlihat semua peserta sebanyak 46 Guru ( Gambar 8 ) memahami dan dapat mengimplemetasikan pengenalan berbasis IT dan juga alat peraga, dari hasil angket semua peserta menilai sangat positif kegiatan ini dan mohon untuk dilakukan kegiatan lanjutan dengan model pembelajaran yang jenis lainnya.

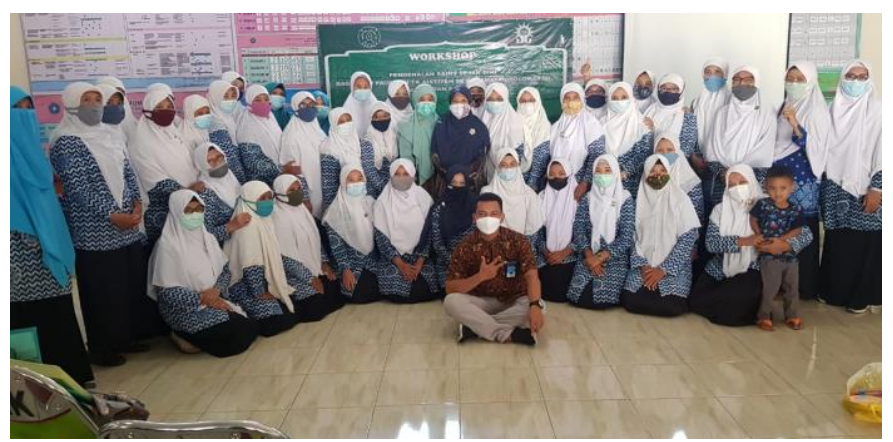

Gambar 8. Pemateri dan peserta pelatihan 


\section{Kesimpulan}

Upaya pengenalan Sains bagi anak usia dini dilakukan untuk 46 Guru PAUD dan TK se kecamatan Polokarto, 2 agenda telah dilakukan yaitu melalui IT menggunakan aplikasi Augmented Reality AR-Animal dan Planet AR, juga melalui Alat Peraga yaitu timbangan dan angka digital. Sebelum dilakukan pelatihan sebagian besar peserta belum memahami bagaimana mengenalkan sains kepada anak, akan tetapi setelah dilakukan pelatihan semua peserta faham dan dapat mengimplementasikan ke anak didik.

\section{Ucapan Terima kasih}

Penulis mengucapkan terima kasih kepada Lembaga Penelitian dan Pengabdian kepada Masyarakat Univeristas Sebelas Maret Surakarta yang telah mendanai kegiatan ini melalui Hibah Program Kemitraan Masyarakat melalui dana non APBN dengan nomer kontrak 261/UN27.22/HK.07.00/2021 dan juga Majelis Pendidikan Dasar dan Menengah Aisyiyah Cabang Blimbing Kabupaten Sukoharjo atas ijin dan Kerjasamanya hingga kegiatan ini dapat terselenggara dengan baik.

\section{Daftar Pustaka}

Ariyanti, T. (2016). Pentingnya Pendidikan Anak Usia Dini Bagi Tumbuh Kembang Anak The Importance of Childhood Education for Child Development. Dinamika Jurnal Ilmiah Pendidikan Dasar, 8(1).

Uce, L. (2017). The golden age: Masa efektif merancang kualitas anak. Bunayya: Jurnal Pendidikan Anak, 1(2), 77-92.

Rizal, M. (2014). Pengaruh pembelajaran inkuiri terbimbing dengan multi representasi terhadap keterampilan proses sains dan penguasaan konsep IPA siswa SMP. Jurnal Pendidikan Sains, 2(3), 159-165.

Narut, Y. F., \& Supardi, K. (2019). Literasi sains peserta didik dalam pembelajaran IPA di indonesia. JIPD (Jurnal Inovasi Pendidikan Dasar), 3(1), 61-69.

Laila, M., Rosnita, R., \& Kaswari, K. Peningkatan Aktivitas Belajar Peserta Didik Menggunakan Metode Percobaan dalam Pembelajaran Sains (Doctoral dissertation, Tanjungpura University).

Izzuddin, A. (2019). Sains dan Pembelajarannya pada Anak Usia Dini. BINTANG, 1(3), 353-365.

Mustika, Y., \& Nurwidaningsih, L. (2018). Pengaruh Percobaan Sains Anak Usia Dini terhadap Perkembangan Kognitif Anak di TK Kartika Siwi Pusdikpal Kota Cimahi. Jurnal Obsesi: Jurnal Pendidikan Anak Usia Dini, 2(1), 94-101.

Anwar, F., Kusumandari, K., Iriani, Y., \& Yunianto, M. (2020). Pelatihan Pemanfaatan Alat Peraga gagi Guru SD Muhammadiyah Di Sukoharjo Dalam Menghadapi Era Revolusi Industri 4.0. Adi Widya: Jurnal Pengabdian Masyarakat, 4(1). 